\title{
Anatomical factors causing oedema of the lower limb during pregnancy
}

\author{
B. Benninger 1 , 2, 3, 4, 5, 6, 7, 8, T. Delamarter ${ }^{1}$
}

\begin{abstract}
${ }^{1}$ Department of Medical Anatomical Sciences, Western University of Health Sciences, COMP-Northwest, Lebanon, United States

2Department of Neuromuscular Medicine, Western University of Health Sciences, COMP-Northwest, Lebanon, United States

${ }^{3}$ Department of Family Practice, Western University of Health Sciences, COMP-Northwest, Lebanon, United States

${ }^{4}$ Samaritan Health Services Orthopaedics, Residency Faculty, Corvallis, United States

${ }^{5}$ Samaritan Health Services General Surgery, Residency Faculty, Corvallis, United States

${ }^{6}$ Department of Oral Maxillofacial Surgery, Oregon Health and Science University, Portland, United States

${ }^{7}$ Department of Surgery, Oregon Health and Science University, Portland, United States

${ }^{8}$ Department of Orthopaedics and Rehabilitation, Oregon Health and Science University, Portland, United States
\end{abstract}

[Received 6 March 2012; Accepted 19 May 2012]

Background: The objective of this study was to investigate the morphology of the common iliac artery and vein (CIA\&V) comparing right and left sides in females versus males. Pregnant women favour lying on one side at rest and during sleep. The reason for this may be due to the morphology and orientation between the CIA\&V. Virtually all women during their pregnancy suffer from lower limb swelling. This study provides an anatomical explanation for the propensity to lie consistently on one side, for lower limb swelling, and offers prevention measures.

Materials and methods: A literature search was conducted on anatomical texts, atlases, journals, and websites regarding the morphology and orientation of the right and left CIA\&V, lower limb oedema, and sleeping positions during pregnancy. Measurements from 15 dissected cadavers were conducted on the right and left CIA\&V.

Results: The literature search revealed very limited studies on the morphology and orientation of the right and left CIA\&V with no studies relating this orientation to lower limb oedema or sleeping positions during pregnancy. Cadaver dissection revealed a relatively direct anterior to posterior orientation left CIA\&V and an oblique lateral to medial right CIA\&V.

Conclusions: This study suggests an explanation of why women lie on their left side when resting and sleeping during the third trimester due to the clinically relevant anatomy between the CIA\&V. (Folia Morphol 2013; 72, 1: 67-71)

Key words: common iliac arteries and veins, lower limb oedema, swollen ankles, third trimester sleeping habits

\section{INTRODUCTION}

The common iliac veins are recognised as the joining of the external and internal iliac veins as they ascend within the pelvis towards the abdo- men. Their attitude transfers right of the midline and forms the inferior vena cava. The common iliac arteries descend from the aorta, which classically lies left of the midline within the abdomen,

Address for correspondence: B. Benninger, MD, MSc, Western University of Health Sciences, COMP, Northwest, Oregon Health and Sciences University, Lebanon, OR, 97355, United States, e-mail: bbenninger@westernu.edu 


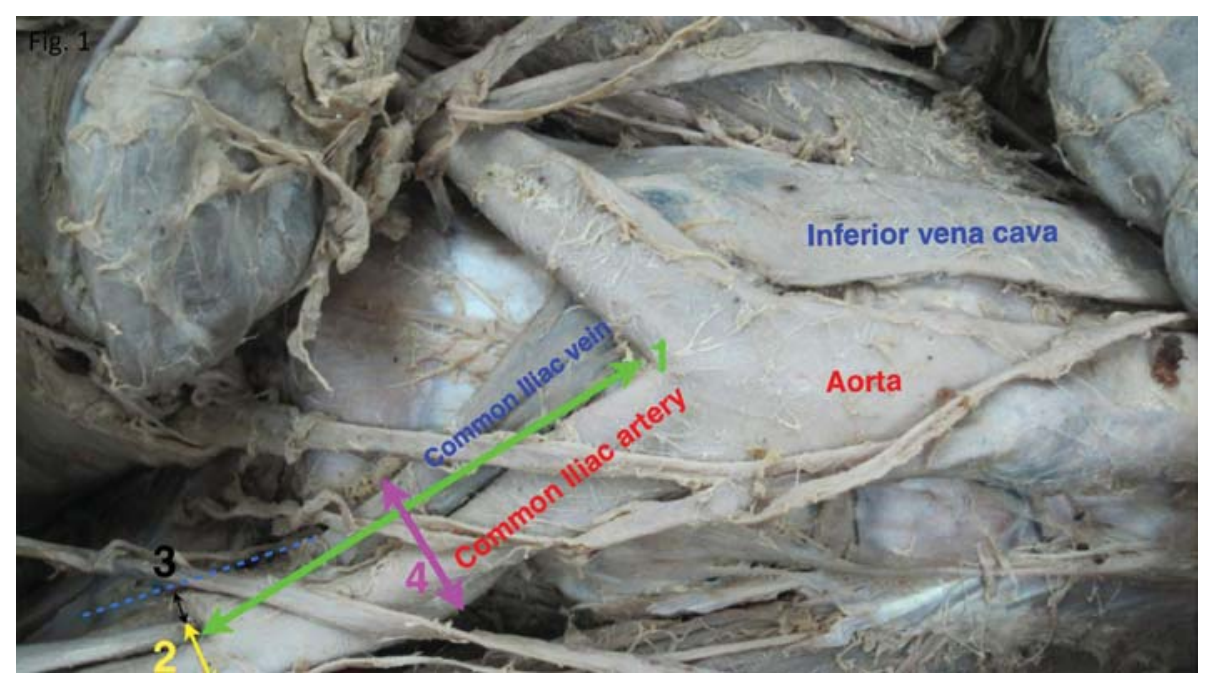

Figure 1. Deep dissection of the abdominopelvic region revealing the measurements conducted on the common iliac artery and vein; 1 - bifurcation of aorta; 2 - bifurcation of left common iliac artery and measures the width of the left external iliac artery; 3 - bifurcation of left common iliac vein and measures only the uncovered width of the left external iliac tein; 4 — the combined width of the left common iliac vein and artery.

into the pelvis bifurcating into external and internal branches.

The common iliacs have become involved with vascular surgery and are capable of transmitting a guide wire to allow arteriograms of the aorta and cardiac vessels as a recipient of the Seldinger technique [27]. Bypass vascular surgery and clots can occur involving both common iliac arteries and veins. There has also been a great deal of interest in the orientation of the right common lliac artery as it crosses over the left common iliac vein because of the hypothesised relationship between iliac vein compression syndrome (IVCS) and deep venous thrombosis (DVT) in the lower extremities $[2-4,10,11,18,21,24,28]$.

Pregnancy, in particular during the third trimester, causes swelling of the distal lower limbs. This can lead to pain from excessive swelling of the feet, problems with footwear, and an antalgic gait. Observations reveal a left and right side difference regarding the appearance and severity of ankle swelling. Studies of IVCS and DVT have also revealed an increased percentage of left lower limb DVT in pregnant women $[4,20]$. Furthermore, the majority of pregnant women in their third trimester favour lying on one side of their body more than the other. A documented cause for a left-sided sleeping pattern is IVCS and supine hypotensive syndrome during pregnancy. Women with this syndrome prefer to lie on their left side, which transfers the pressure of the foetus from the collapsible right-sided IVC to the much more compression resistant left-sided aorta [7, 8, 15-17]. Interestingly, pregnant women who do not suffer from IVCS prefer sleeping on their left side.
The objective of this study was to analyse the anatomical orientation of the common iliac artery and vein $(C I A \& V)$ and see if the morphology was different from one side to the other, which could explain swelling of the distal extremity of the lower limb and sleeping behaviour without IVC compression.

\section{MATERIALS AND METHODS}

A literature search was conducted on anatomical texts, atlases, journals, and websites regarding the morphology and orientation of the CIA\&V, lower limb oedema, and sleeping patterns during pregnancy. Deep dissection was conducted on 15 cadaver pelvises ( 8 male, 7 female, age 44-89, average 76.1 years). Four measurements were made to the right and the left sides: (1) The first measurement was from the bifurcation of the common iliac to the bifurcation of the internal and external iliac (Bif 1 to Bif 2), which was used to find a location midway between Bif 1 and Bif 2 as the point of measurement 4; (2) A measurement of the combined visual width of the CIA and CIV at Bif 2; (3) The visual width of only the vein was measured at the edge of the artery to the border of the vein at Bif 2; (4) A measurement of the combined visual width of the CIA and CIV at the midpoint between Bif 1 and Bif 2. Measurements 2 and 4 were averaged to find the average width of the $\mathrm{CIA}$ and CIV from Bif 1 to Bif 2 (Fig. 1).

\section{RESULTS}

A literature search of anatomical and specialty texts/ atlases revealed relatively few (32\%) adequate pictorial representations of the orientation of the CIA\&V to 
CIA/CIV width [mm]

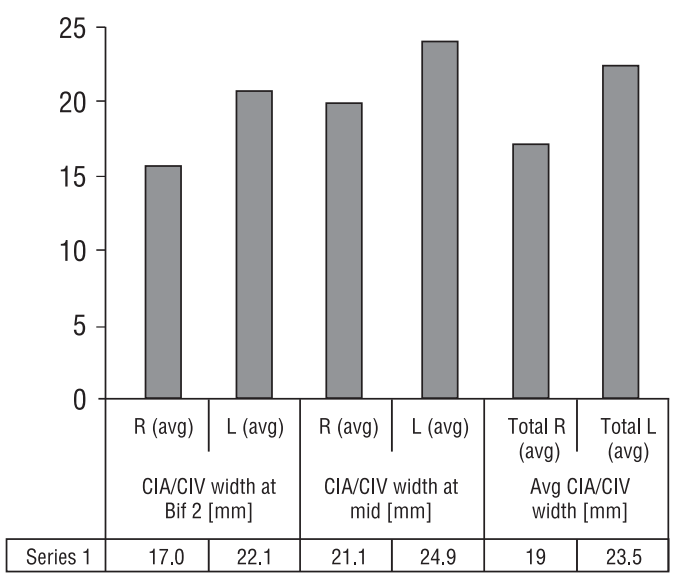

CIV unvovered width [mm]

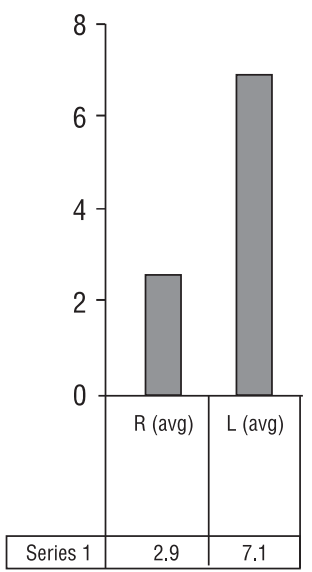

Lenght Bif 1 to Bif $2[\mathrm{~mm}]$

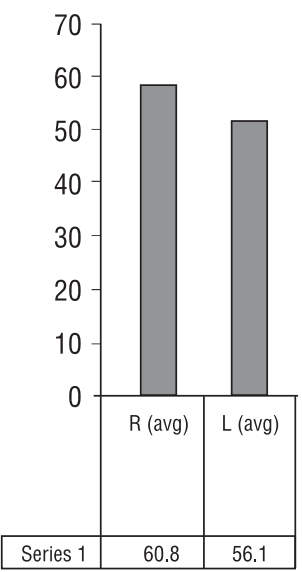

Figure 2. Graphs revealing the average results from the five measurements conducted on the common iliac artery (CIA) and common iliac vein (CIV).

each other $[1,5,6,9,12-14,19,22,23,25,26,29-33$, $35,36]$, and only one anatomical text $(5 \%)$, the $40^{\text {th }}$ edition of Gray's anatomy [32], accurately describes this orientation. A literature search of journal articles revealed multiple studies relating to the CIA\&V; however, the focus of the majority of these articles was IVCS and DVT, not the distal morphology of the CIA\&V. Measurements of the CIA\&V in these articles included the length prior to bifurcation [34], distance from aortic bifurcation to the sacral promontory [10, 34], distance between the right CIA (RCIA) and the left CIV (LCIV) $[10,34]$, and the width of the uncovered LCIV [10]. A literature search of sleeping patterns and lower limb oedema during pregnancy revealed that IVCS causes pregnant women to sleep on their left side because a supine sleeping position can completely occlude the IVC forcing venous return via alternative collateral channels, usually the lumbar veins $[8,17]$. There were no studies relating lower limb oedema and a left-sided sleeping pattern to the orientation of the LCIA\&V and RCIA\&V; however, one study did note that the LCIV was more markedly affected by compression of the foetus than the RCIV [17].

Deep dissection of 15 embalmed abdominal pelvis specimens was performed. On observation, all 15 specimens revealed a difference between RCIA and LCIA and vein orientation. Measurements from four locations revealed the following. (1) The length of the CIA\&V from the aortic bifurcation to the bifurcation into the external and internal iliacs averaged $60.8 \mathrm{~mm}$ on the right and $56.1 \mathrm{~mm}$ on the left. (2) The average width of the CIA\&V immediately prior to the bifurcation of the common iliacs into the internal and external iliacs averaged $17.0 \mathrm{~mm}$ on the right and $22.1 \mathrm{~mm}$ on the left. (3) The average width of the uncovered CIV at this same location averaged $2.9 \mathrm{~mm}$ on the right and $7.1 \mathrm{~mm}$ on the left. (4) The average width of the CIA\&V midway between the aortic bifurcation and the bifurcation into external and internal iliacs was $21.1 \mathrm{~mm}$ on the right and $24.9 \mathrm{~mm}$ on the left. Finally, the two average width measurements ( 2 \& 4) were averaged to acquire overall averages of the CIA\&V, which were $19 \mathrm{~mm}$ on the right and $23.5 \mathrm{~mm}$ on the left (Fig. 2).

\section{DISCUSSION}

The cause of the swelling of the distal lower limb extremities during the third trimester of pregnancy is multifactorial, including inferior vena caval syndrome, supine hypotensive syndrome, posture, gait, etc. $[4,7,8,15-17,20,24]$. The authors would like to add to this by suggesting the orientation of the LCIA\&V is a significant factor in pregnant women causing lower limb swelling. The authors believe the majority of pregnant women will notice right ankle/foot swelling initially, then bilateral as pregnancy progresses.

The majority of the veins within the body are anterior or superficial while arteries are deep or posterior; however, in this particular instance, the orientation is reversed. Since arteries maintain their integrity and veins are collapsible, a decreased venous return can be explained by the anteriorly oriented arteries, which compress the posteriorly positioned veins. It has been hypothesised by the authors that a significant factor causing the swelling may be due to the orientation of the $C I A \& V$ to each other. The dissections revealed such a pattern: the RCIA\&V lie in an anterior/posterior attitude to each other and LCIA\&V revealed a common pattern of a side-by-side attitude (Fig. 3). 


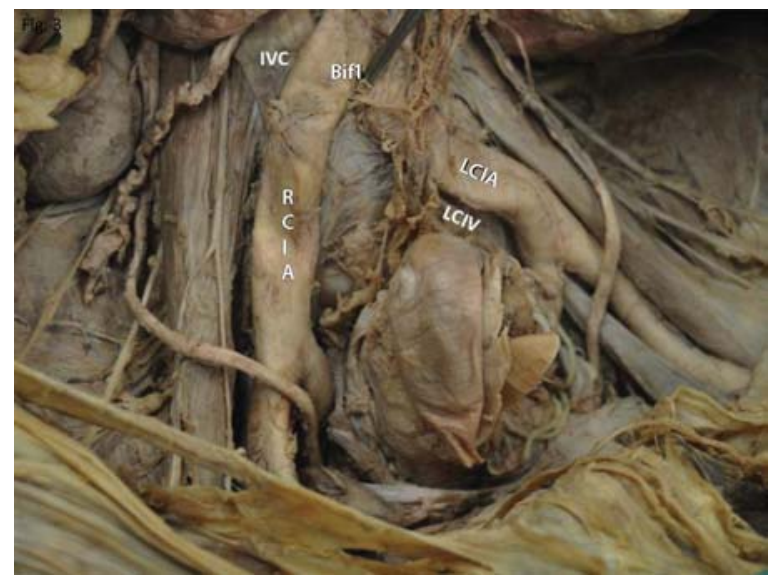

Figure 3. Deep dissection of the abdominopelvic region revealing the anterior/posterior attitude of the right common iliac artery and vein (RCIA, RCIV) and the lateral/medial attitude of the left common iliac artery and vein (LCIA, LCIV); IVC — inferior vena cava; Bif1 — aortic bifurcation.

Some studies have mentioned that the LCIV is medial to the RCIV and one study measured the width of the uncovered LCIV; however, no known studies provided specific measurements of the RCIA\&V and LCIA\&V to each other inferior to the aortic bifurcation. The measurements conducted in this study revealed that the LCIA\&V has a consistently greater width than the RCIA\&V due to the medial/lateral orientation of the LCIA\&V compared to the anterior/posterior orientation of the RCIA\&V. During the third trimester, a fetus can apply pressure anterior to (on top of) the RCIA, which compresses the RCIV directly beneath it (Figs. 4, 5).

Though IVCS and supine hypotensive syndrome are well-documented causes of oedema during pregnan$c y$, particularly during the third trimester, this does not explain the unpublished data from the authors, which revealed that the symptoms and signs of the swelling of the distal lower extremities during the third trimester are generally first noted on the right side. This may be related to the orientation of the RCIA\&V compared to the LCIA\&V and may help explain why many third trimester women prefer to lie on their left side, which decreases the swelling from the distal lower extremities. Further, according to Macklon et al. [20], a left lateral lying position increases the flow velocity in the LCIV providing anatomical and aetiological proof of the preferred left lying position for women during pregnancy. To support this and the author's hypothesis regarding the orientation of the LCIA\&V with its link to lower limb swelling and sleep positions, they will be collaborating with other institutions to study right versus left sided femoral venous pressure. If the left femoral vein has a lower total pressure than the

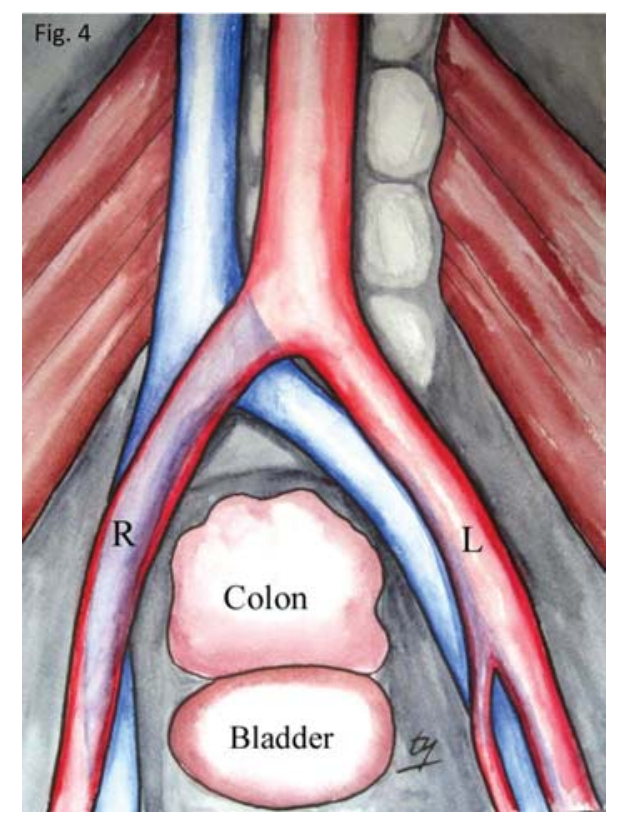

Figure 4. Illustration displaying the accurate morphology and orientation of the common iliac artery and vein.

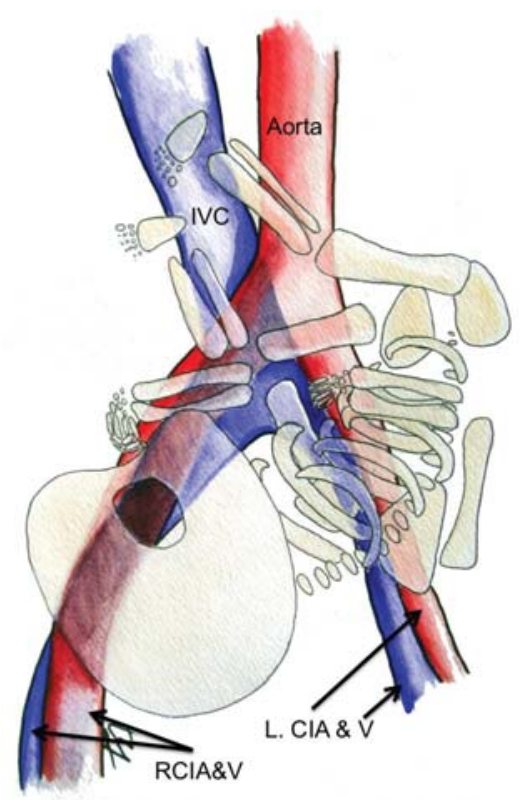

Figure 5. Illustration displaying the pressure place on the right (RCIA\&V) and left (LCIA\&V) common iliac artery and vein by a foetus during the third trimester; IVC — inferior vena cava.

right femoral vein, inferior vena cava compression could be ruled out because it suggests the cause is unilateral (most likely due to the orientation of the LCIA\&V versus the RCIA\&V).

Clinically, those health care providers who assist or treat pregnant women can provide an explana- 
tion of why the swelling may occur and how to minimise the swelling (by lying and sleeping on one's left side). Clinicians should detail how lying on one's left side can help to alleviate IVCS and diminish the amount of LCIV compression, both of which are factors in lower limb swelling. The ability of a clinician to anatomically explain why a woman may acquire swelling of the distal lower extremities may alleviate anxiety (a better-informed patient is a less anxious patient).

\section{CONCLUSIONS}

This study suggests a frequent pattern between the RCIA\&V and LCIA\&V that may add to the aetiology of swollen ankles during the third trimester of pregnancy as well as provide an explanation for leftsided sleeping behaviour during this time.

\section{ACKNOWLEDGEMENTS}

The authors would like to thank Tiffany Yee for the anatomical illustrations and Amy Swofford for her assistance in the lab with data collection. We would also like to thank B. Davidson for manuscript support and all the donor cadavers whose gift enabled this study to be conducted. Special thanks to The McDaniel Clinical Anatomy Research Lab.

\section{REFERENCES}

1. Abrahams PH, Boon JM, Spratt JD (2008) McMinn's clinical atlas of human anatomy. 6 Ed. Mosby Elsevier, London.

2. Barrellier M, Lexin B, Monsalilier J (2011) Isolated iliac deep venous thrombosis. Study of 48 cases seen in 7 years among 18,297 echo-Doppler evaluations of the lower limbs. J Maladies Vasculaires, 5: 290-298.

3. Blanco-Molina A, Rota L, Di Micco P, Brenner B, TrujilloSantos J, Ruiz-Gamietea A, Monreal M, for the RIETE Investigators (2009) Venous thromboembolism during pregnancy, pospartum or during contraceptive use. Thrombosis Haemostasis, 2: 306-311.

4. Chan W-S, Spencer FA, Ginsberg JS (2010) Anatomic distribution of deep vein thrombosis in pregnancy. Can Med Assoc J, 7: 657-660.

5. Chung KW, Chung HM (2008) Gross anatomy. 6 Ed. Lippincott Williams \& Wilkins, Baltimore.

6. Clemente CD (2007) Anatomy: a regional atlas of the human body. 5 Ed. Lippincott Williams \& Wilkins, Philadelphia.

7. Davison J (1997) Edema in pregnancy. Kidney Int Suppl, 59: 90-96.

8. DeGriorgio F, Grassi VM, Vetrugno G, d'Aloja E, Pascali VL, Arena V (2012) Supine hypotensive syndrome as the probable cause of both maternal and fetal death. J Forensic Science, 57: 1646-1649.

9. Drake RL, Vogl AW, Mitchell AWM, Tibbits RM, Richardson PW (2008) Gray's atlas of anatomy. Churchill Livingstone, Philadelphia.

10. Ebraheim NA, Xu R, Farooq A, Yeasting RA (1996) The quantitative anatomy of the iliac vessels and their relation to anterior lumbosacral approach. J Spinal Dis, 9: 414-417.
11. Fraser DGW, Moody AR, Martel A, Morgan PS (2004) Reevaluation of iliac compression syndrome using magnetic resonance imaging in patients with acute deep venous thromboses. J Vasc Surg, 40: 604-611.

12. Gilroy AM, MacPherson BR, Ross LM (2008) Atlas of anatomy. Thieme Medical Publishers, Inc. New York.

13. Gosling JA, Harris PF, Humpherson JR, Whitmore I, Willian PLT (2008) Human anatomy: color atlas and textbook. 5 Ed. Mosby Elsevier, Philadelphia.

14. Grant JCB (1962) Grant's atlas of anatomy. 5 Ed. The Williams \& Wilkins Co., Baltimore.

15. Harris R (1976) The etiology of inferior vena caval obstruction and compression. CRC Crit REv Clin Radiol Nucl Med, 8: 57-86.

16. Howard BK, Goodson JH, Mengert WF (1953) Supine hypotensive syndrome in late pregnancy. Obstetrics Gynecol, 1: 371-377.

17. Kerr M, Scott D, Samuel E (1964) Studies of the inferior vena cava in late pregnancy. Br Med J, 1: 532-533.

18. Kibbe RM, Ujiki M, Goodwin AL, Eskandari M, Yao J, Matsumura J (2004) Iliac vein compression in an asymptomatic patient population. J Vasc Surg, 39: 937-943.

19. Langman J, Woerdeman MW (1978) Atlas of medical anatomy. W. B. Saunders Company, Philadelphia.

20. Macklon NS, Greer IA, Bowman AW (1997) An ultrasound study of gestational and postural changes in the deep venous system of the leg in pregnancy. Br J Obstetrics Gynaecol, 104: 191-197.

21. Moller I, Eickhoff JH, Hansen HJ, Lindewald H (1980) The iliac vein compression syndrome: a case report with a review of the literature. Acta Cgur Scabd, 502: 141-145.

22. Moore KL (2010) Clinically oriented anatomy. 6 Ed. Williams \& Wilkins, Baltimore.

23. Moses KP, Banks JC, Nava PB, Peterson D (2005) Atlas of clinical gross anatomy. Elsevier Mosby, Philadelphia.

24. Negus D, Pinto DJ, LeQuesne LP, Brown N, Chapman M (1968) Compression and band formation at the mouth of the left common iliac vein. Br J Surg, 55: 369-374.

25. Netter $F$ (2011) Atlas of human anatomy. 5 Ed. Elsevier, Philadelphia.

26. Rohen JW, Yokochi C, Lutjen-Drecoll E (2006) Color atlas of anatomy: a photographic study of the human body. 6 Ed. Pippincott Williams \& Wilkins, Baltimore.

27. Seldinger SI (1952) Catheter replacement of the needle in percutaneous arteriography: a new technique. Congress of Northern Association of Medical Radiology, pp. 368-376.

28. Shebel ND, Whalen CC (2005) Diagnosis and management of iliac vein compression syndrome. J Vasc Nursing, 23: 10-17.

29. Slaby FJ, McCune SK, Summers RW (1994) Gross anatomy in the practice of medicine. Lea \& Febiger, Malvern.

30. Snell RS (2004) Clinical anatomy. 7Ed. Lippincott Williams \& Wilkins, Baltimore.

31. Sobotta J (2000) Sobotta atlas of human anatomy. Vol. 2. 13 Ed. Lippincott Williams \& Wilkins, Philadelphia.

32. Standring S (2008) Gray's anatomy: the anatomical basis of clinical practice. $40 \mathrm{Ed}$. Elsevier, Spain, Standring.

33. Tank PW, Gest TR (2009) Atlas of anatomy. Lippincott Williams \& Wilkins, Baltimore.

34. Tribus $C$, Belanger $T$ (2001) The vascular anatomy anterior to the L5-S1 disc space. Spine, 26: 1205-1208.

35. Uflacker R (2007) Atlas of vascular anatomy: an angiographic approach. 2 Ed. Lippincott Williams \& Wilkins, Philadelphia.

36. Woddburne RT, Burkey WE (1994) Essentials of human anatomy. 9 Ed. Oxford University Press, New York. 